Check for updates

Cite this: RSC Adv., 2017, 7, 46215

Received 24th August 2017

Accepted 25th September 2017

DOI: $10.1039 / \mathrm{c} 7 \mathrm{ra09399c}$

rsc.li/rsc-advances

\title{
Electromagnetic and wave absorbing properties of Fe-doped polymer-derived SiCN ceramics
}

\begin{abstract}
Youzhi Wang, ${ }^{\text {ab }}$ Yurun Feng, ${ }^{* c}$ Xue Guo, ${ }^{c}$ Yu Liu ${ }^{c}$ and Hongyu Gong (DD *c
Fe-doped polymer-derived SiCN ceramics were synthesized by a precursor conversion method with different contents of nano- $\mathrm{Fe}_{2} \mathrm{O}_{3}$. The phase composition and microstructure were characterized by $X R D, S E M$ and TEM. The results revealed that $\alpha$-Fe and graphite phases were generated during the synthetic process. The electromagnetic and wave absorbing properties of the Fe-doped SiCN ceramics were analyzed with different amounts of nano- $\mathrm{F}_{2} \mathrm{O}_{3}$ over the frequency range of $2-18 \mathrm{GHz}$. The existence of $\alpha$-Fe and graphite phases improved the electromagnetic properties of the materials greatly. The reflectance and electromagnetic attenuation coefficient of Fe-doped SiCN ceramics ( 15 wt $\% \mathrm{~F}_{2} \mathrm{O}_{3}$ ) reached $-11 \mathrm{~dB}$ and 325 at $10.5 \mathrm{GHz}$, respectively, which indicated that the Fe-doped SiCN ceramics possessed excellent absorbing properties.
\end{abstract}

\section{Introduction}

With the rapid development of information technology, the interference between different sources of electromagnetic waves always leads to a decrease in the accuracy of data transmission and can even lead to the failure of the electronic device. Therefore, technology that effectively shields or absorbs electromagnetic waves is urgently needed. Although electromagnetic shielding materials are helpful to block the electromagnetic interference, they are incapable of weakening the electromagnetic wave fundamentally. However, the electromagnetic wave absorption materials can convert the energy of the electromagnetic wave into other forms, such as mechanical energy, thermal energy and power energy, thereby almost eliminating the influence of the electromagnetic wave., ${ }^{\mathbf{1 , 2}}$ Traditional absorbing materials such as ferrite, the metal alloy, carbide ceramics, carbon-based materials, etc. present good absorbing intensity, but narrow absorption bands, ease of oxidation and high density limit their development.

Recently, polymer derived SiCN ceramics have attracted many interests due to the unique microstructures with carbon nano-domains, ${ }^{3}$ excellent thermal stability, ${ }^{4}$ oxidation and creep resistance ${ }^{5-7}$ and outstanding electric conductivity, ${ }^{8}$ which make them popular in applications of anode materials in lithium battery ${ }^{\mathbf{9 1 0}}$ and high-temperature sensing devices. ${ }^{\mathbf{1 1}}$ However, few researches put emphasis on the dielectric and microwave absorption properties of SiCN ceramics. Actually the

${ }^{a}$ State Key Laboratory for Hydraulic Engineering Simulation and Safety, Tianjin University, Tianjin 250061, P. R. China

${ }^{b}$ School of Civil Engineering, Shandong University, Jinan 250061, P. R. China ${ }^{c}$ Key Laboratory for Liquid-Solid Evolution \& Processing of Materials of Ministry of Education, Shandong University, Jinan 250061, P. R. China. E-mail: fengyurun@ mail.sdu.edu.cn; hygong@sdu.edu.cn
SiCN ceramics have excellent dielectric properties in X-band. ${ }^{\mathbf{1 2}}$ Additionally, the incorporation of magnetic materials (metallic fillers, such as Fe and its compounds) may offer new magnetic capabilities and microwave absorbing properties for the SiCN ceramics. Ralf Hauser et al. ${ }^{13}$ discussed the influence of Fe and Co addition on the magnetization of metal-containing SiCN ceramics. The metallic SiCN ceramics exhibit outstanding ferromagnetic behavior, indicating that the existence of magnetic materials could improve the dielectric properties and magnetic performance greatly.

In this work, the polymer-derived SiCN ceramics were synthesized by precursor conversion method with nano- $\mathrm{Fe}_{2} \mathrm{O}_{3}$ as magnetic filler. The effect of nano- $\mathrm{Fe}_{2} \mathrm{O}_{3}$ (6 wt\%, $12 \mathrm{wt} \%$, $15 \mathrm{wt} \%, 18 \mathrm{wt} \%$ ) on the phase composition, microstructure and electromagnetic properties of the Fe-doped SiCN ceramics were analyzed.

\section{Material and methods}

Polysilazane (HTT1800, Haiyi Technology and Trading Co. Ltd., Shanghai) was used as the precursor. Dicumyl peroxide (DCP, $99 \%$, Aladdin) was used as cross linking agent. The nano- $\mathrm{Fe}_{2} \mathrm{O}_{3}$ $\left(D_{50}=20 \mathrm{~nm}, \alpha-\mathrm{Si}_{3} \mathrm{~N}_{4}>93 \%\right.$, Beiing Tsinghua Unisplend or Founder High-Tech Ceramics Co. Ltd.) was added as magnetic filler. The HTT1800 and DCP were mixed at $70{ }^{\circ} \mathrm{C}$ and crosslinked at $600{ }^{\circ} \mathrm{C}$ under nitrogen flow atmosphere. After crushing and ball milling, the precrosslinked powder was uniformly mixed with different amounts of nano- $\mathrm{Fe}_{2} \mathrm{O}_{3}(6 \mathrm{wt} \%, 12 \mathrm{wt} \%$, $15 \mathrm{wt} \%$ and $18 \mathrm{wt} \%$ ). The mixed powders were pressed into green compacts and sintered at $1100{ }^{\circ} \mathrm{C}$ for $2 \mathrm{~h}$ under $\mathrm{N}_{2}$ atmosphere.

The phase compositions of samples were analyzed by the Xray diffraction (XRD, X'pert Pro MPD, Japan). The 
microstructure characterization of SiCN ceramics was performed using SEM equipped with EDS (SU-70, Hitachi Co., Japan) and TEM (JEM-1200EX). The low-frequency permittivity of samples was identified by LCR digital electric bridge (TH2826, Changzhou Tonghui Electronic Co., Ltd). The permittivity and permeability of samples at frequency range of 2-18 GHz were analyzed by coaxial transmission reflection method through vector network analyzer (VNA, N 5244A, Agilent, USA). The sample was crushed and ground into fine powders, and then prepared into $\Phi_{7}-\Phi_{3}$ coaxial rings with $2 \mathrm{~mm}$ thickness. The reflectance $(R)$ and electromagnetic attenuation coefficient $(\alpha)$ were calculated by the following equations:

$$
\begin{gathered}
R=20 \log _{10}\left|\frac{Z_{\text {in }}-1}{Z_{\text {in }}+1}\right| \\
Z_{\text {in }}=\sqrt{\frac{\mu_{\mathrm{r}}}{\varepsilon_{\mathrm{r}}}} \tanh \left(\frac{\mathrm{j} 2 \pi f d}{c} \sqrt{\mu_{\mathrm{r}} \varepsilon_{\mathrm{r}}}\right) \\
\alpha=\frac{\pi f}{c} \sqrt{2 \mu^{\prime} \varepsilon^{\prime}} \sqrt{\frac{\varepsilon^{\prime \prime} \mu^{\prime \prime}}{\varepsilon^{\prime} \mu^{\prime}}-1+\sqrt{\left(\frac{\varepsilon^{\prime \prime} \mu^{\prime \prime}}{\varepsilon^{\prime} \mu^{\prime}}\right)^{2}+\left(\frac{\varepsilon^{\prime \prime}}{\varepsilon^{\prime}}\right)^{2}+\left(\frac{\mu^{\prime \prime}}{\mu^{\prime}}\right)^{2}+1}}
\end{gathered}
$$

where $Z_{\text {in }}$ was input impedance, $\varepsilon_{\mathrm{r}}$ was the permittivity, $\mu_{\mathrm{r}}$ is the relative permeability, $\varepsilon^{\prime}$ was the real part of permittivity, $\varepsilon^{\prime \prime}$ was the imaginary part of permittivity, $\mu^{\prime}$ was the real permeability, $\mu^{\prime}$ was the imaginary permeability, $f$ was the frequency of electromagnetic wave, $c$ was the speed of light and $d$ was the thickness of samples.

\section{Results and discussion}

Fig. 1 shows the XRD patterns of Fe-doped SiCN ceramics with different contents of nano- $\mathrm{Fe}_{2} \mathrm{O}_{3}$ powders. The sample exhibited amorphous diffraction peaks, and the main crystalline phases were $\alpha-\mathrm{Fe}$, and graphite. Additionally, the intensity of above peaks increased with the rising amount of nano- $\mathrm{Fe}_{2} \mathrm{O}_{3}$. The transformation of nano- $\mathrm{Fe}_{2} \mathrm{O}_{3}$ to $\alpha$-Fe could be attributed to the formation of inner reductive atmosphere of hydrocarbons and hydrogen $\left(\mathrm{C}_{x} \mathrm{H}_{y}, \mathrm{H}_{2}\right)$ during the pyrolysis process. ${ }^{14-16}$ According to the Scherrer equation, ${ }^{17}$ the size of $\alpha$-Fe crystallites and graphite could be calculated to be about $35 \mathrm{~nm}$ and $20 \mathrm{~nm}$, indicating the simultaneous formation of $\alpha$-Fe and graphite crystallite in the Fe-doped SiCN ceramics.

Fig. 2 represents the SEM micrographs of Fe-doped SiCN ceramics with different contents of nano- $\mathrm{Fe}_{2} \mathrm{O}_{3}$. It showed typical amorphous structure and large amounts of pores existed, meanwhile some minor second phase grain existed in the gap of large particles. The pores might be generated by the structural rearrangement and gas evolution process during the precursor conversion transformation. EDS was applied to analysis the element composition of the particle in the large particles and the grains in the gap.

The EDS spectra of Fe-doped SiCN ceramics with $12 \mathrm{wt} \%$ nano-Fe $\mathrm{O}_{3}$ (Fig. 2(b) 1 and 2) were shown in Fig. 3. According to the elemental analysis, the main elements in the large particles

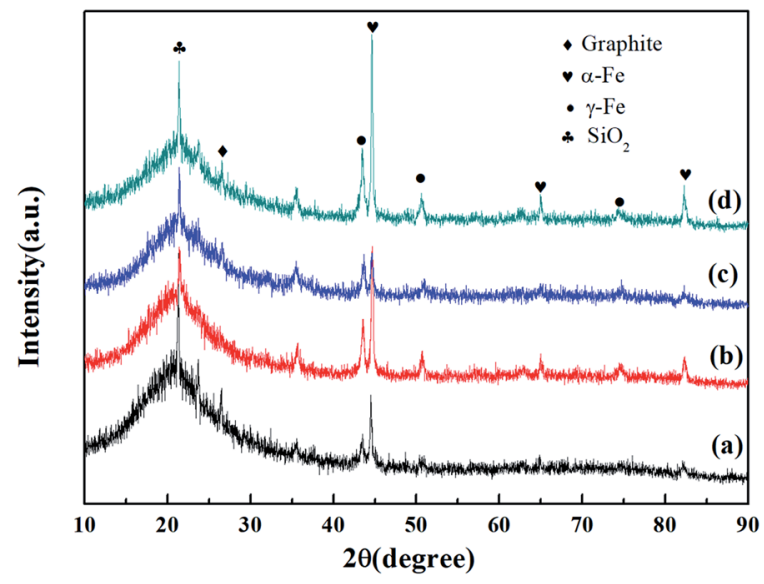

Fig. 1 XRD patterns of Fe-doped SiCN ceramics with different contents of nano- $\mathrm{Fe}_{2} \mathrm{O}_{3}$ (a) 6 wt\%; (b) 12 wt\%; (c) 15 wt\%; (d) 18 wt\%.

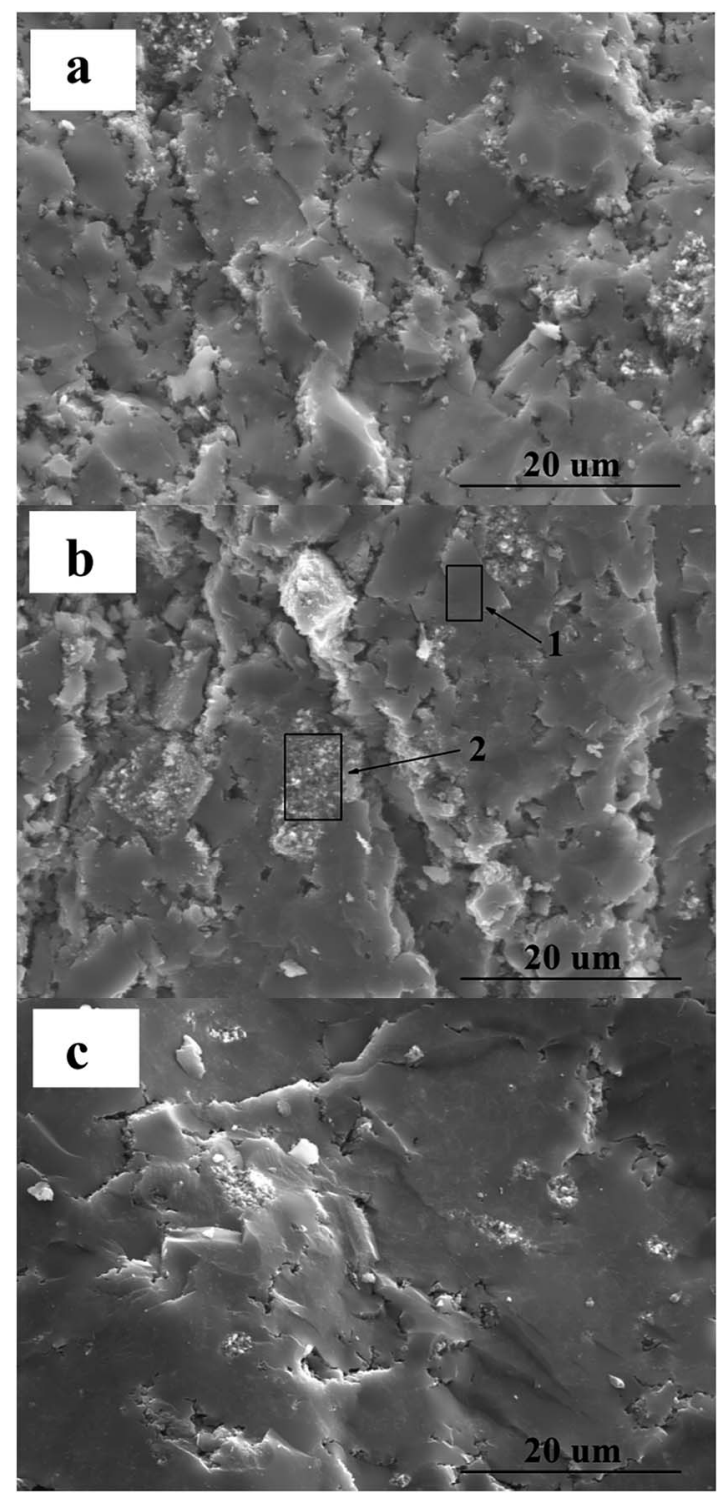

Fig. 2 SEM micrographs of Fe-doped SiCN ceramics with different contents of nano- $\mathrm{Fe}_{2} \mathrm{O}_{3}$ (a) $6 \mathrm{wt} \%$; (b) $12 \mathrm{wt} \%$; (c) $15 \mathrm{wt} \%$. 

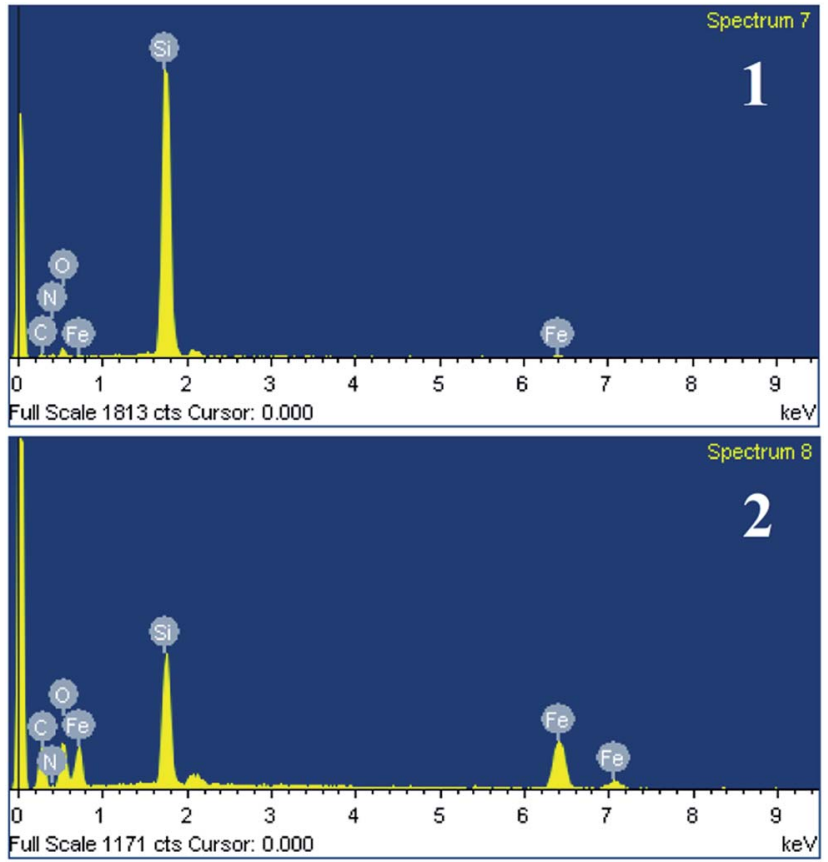

Fig. 3 EDS spectra of Fe-doped SiCN ceramics with 12 wt\% nano$\mathrm{Fe}_{2} \mathrm{O}_{3}$ (panels 1 and 2 stand for EDS spectra of portions 1 and 2 in Fig. 2b).

(Fig. 2(b) area 1) were Si, C, N, indicating that the large particles were consisted of SiCN network frame structure. And the Fe element was hard to be detected in this area. However, the Fe elements $(14.75 \%)$ and $C$ elements could be easily detected in the second phase grains (Fig. 2(b) area 2), which was consistent with the XRD investigations where $\alpha$-Fe was found as the main crystalline phase. Therefore, the $\alpha$-Fe and graphite mainly concentrated in the gaps of large particles.

Fig. 4 shows the HRTEM micrographs (a) and electron diffraction pattern (b) of Fe-doped SiCN ceramics with 15 wt\% nano- $\mathrm{Fe}_{2} \mathrm{O}_{3}$. The grain size of spherical crystallites (Fig. 4(a)) was about $30 \mathrm{~nm}$. Combined with the XRD analysis above, the spherical crystallites might be $\alpha$-Fe. The electron diffraction pattern and parameters of the Fe-doped SiCN ceramics were shown in Fig. 4(b) and Table 1, respectively. The polycrystalline diffraction phenomenon of the sample, indicated the existence of several crystallites, such as $\alpha$-Fe and graphite crystallites. As shown in the diffraction pattern parameters, the main crystal lattice structure $(N=2: 4: 6)$ belonged to body-centered cubic. In addition, the lattice constant (a) calculated in this study was about $2.850 \AA$, which was close to the standard lattice constant (2.866 $\AA$ ) of $\alpha$-Fe, suggesting the generation of $\alpha$-Fe in the Fedoped SiCN ceramics.

Fig. 5 shows the dielectric constants of Fe-doped SiCN ceramics with different contents of nano- $\mathrm{Fe}_{2} \mathrm{O}_{3}$ at 1-5 $\mathrm{MHz}$. Under the same frequency, the appearance of graphite phase particles acting as carriers like space charges and dipoles, resulted in growth of the dielectric constant of Fe-doped SiCN ceramics with the rising amount of nano- $\mathrm{Fe}_{2} \mathrm{O}_{3}$ basically.

The dielectric properties of Fe-doped SiCN ceramics with different contents of nano- $\mathrm{Fe}_{2} \mathrm{O}_{3}$ at the microwave frequency (2-

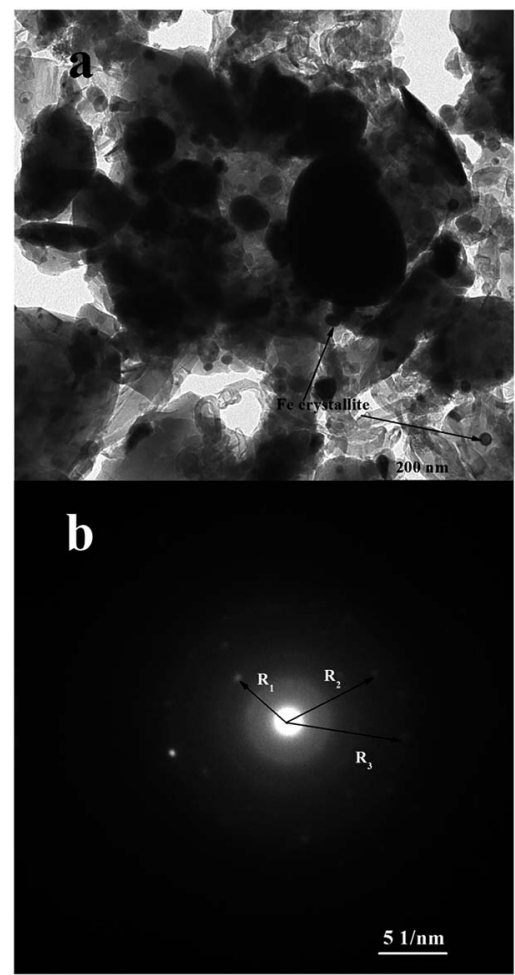

Fig. 4 HRTEM micrographs (a) and electron diffraction pattern (b) of Fe-doped SiCN ceramics with 15 wt\% nano- $\mathrm{Fe}_{2} \mathrm{O}_{3}$.

Table 1 Electron diffraction pattern parameters of Fe-doped SiCN ceramics with $15 \mathrm{wt} \%$ nano- $\mathrm{Fe}_{2} \mathrm{O}_{3}$

\begin{tabular}{llll}
\hline Diffractions circle & 1 & 2 & 3 \\
$R\left(\mathrm{~nm}^{-1}\right)$ & $4.94\left(R_{1}\right)$ & $7.07\left(R_{2}\right)$ & $8.57\left(R_{3}\right)$ \\
$R_{j}{ }^{2} / R_{1}{ }^{2}$ & 1 & 2.04 & 3.01 \\
$N$ & 2 & 4 & 6 \\
$\{h k l\}$ & 110 & 200 & 112 \\
$d(\AA)$ & 2.02 & 1.41 & 1.17 \\
$a(\AA)$ & 2.862 & 2.829 & 2.858
\end{tabular}

$18 \mathrm{GHz}$ ) are shown in Fig. 6. The real part of dielectric constant increased with the rising percentage of nano- $\mathrm{Fe}_{2} \mathrm{O}_{3}$ (Fig. 6(a)). The values of imaginary permittivity (Fig. 6(b)) and the loss tangent (Fig. 6(c)) were both indistinguishable for all samples except that sample with 15 and $18 \mathrm{wt} \%$ nano- $\mathrm{Fe}_{2} \mathrm{O}_{3}$. The resonance peak at $9.5 \mathrm{GHz}$ depended on the change in polarization mechanism of dielectric materials including displacement polarization and turning-direction polarization. ${ }^{18}$ The maximum value of imaginary permittivity and loss tangent of the Fe-doped SiCN ceramics with $15 \mathrm{wt} \%$ nano- $\mathrm{Fe}_{2} \mathrm{O}_{3}$ were 0.65 and 0.13 , respectively. Meanwhile, the increasing of dielectric loss had strengthened the wave absorbing properties.

The magnetic properties of Fe-doped SiCN ceramics with different contents of nano- $\mathrm{Fe}_{2} \mathrm{O}_{3}$ at the microwave frequency (2$18 \mathrm{GHz}$ ) are shown in Fig. 7. The real permeability (Fig. 7(a)) confirmed the ferromagnetic characteristics of the Fe-doped SiCN ceramics. The imaginary permeability (Fig. 7(b)) and magnetic loss angle tangent (Fig. 7(c)) of resonance peaks $12 \mathrm{wt} \%$ and $15 \mathrm{wt} \%$ nano- $\mathrm{Fe}_{2} \mathrm{O}_{3}$ emerged around $10.5 \mathrm{GHz}$, 


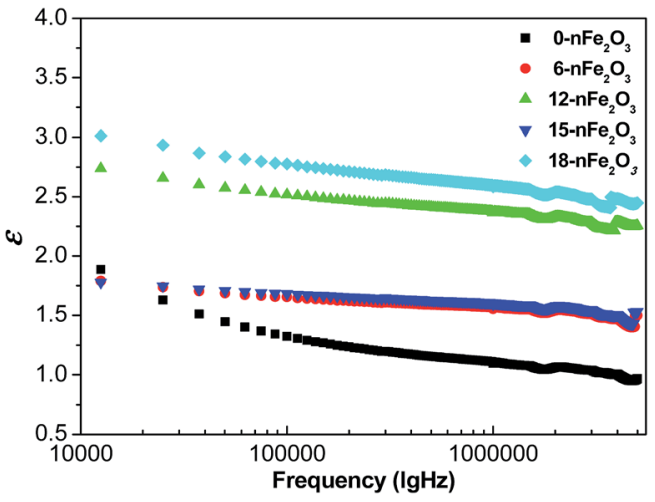

Fig. 5 Dielectric constants of Fe-doped SiCN ceramics with different contents of nano- $\mathrm{Fe}_{2} \mathrm{O}_{3}$.
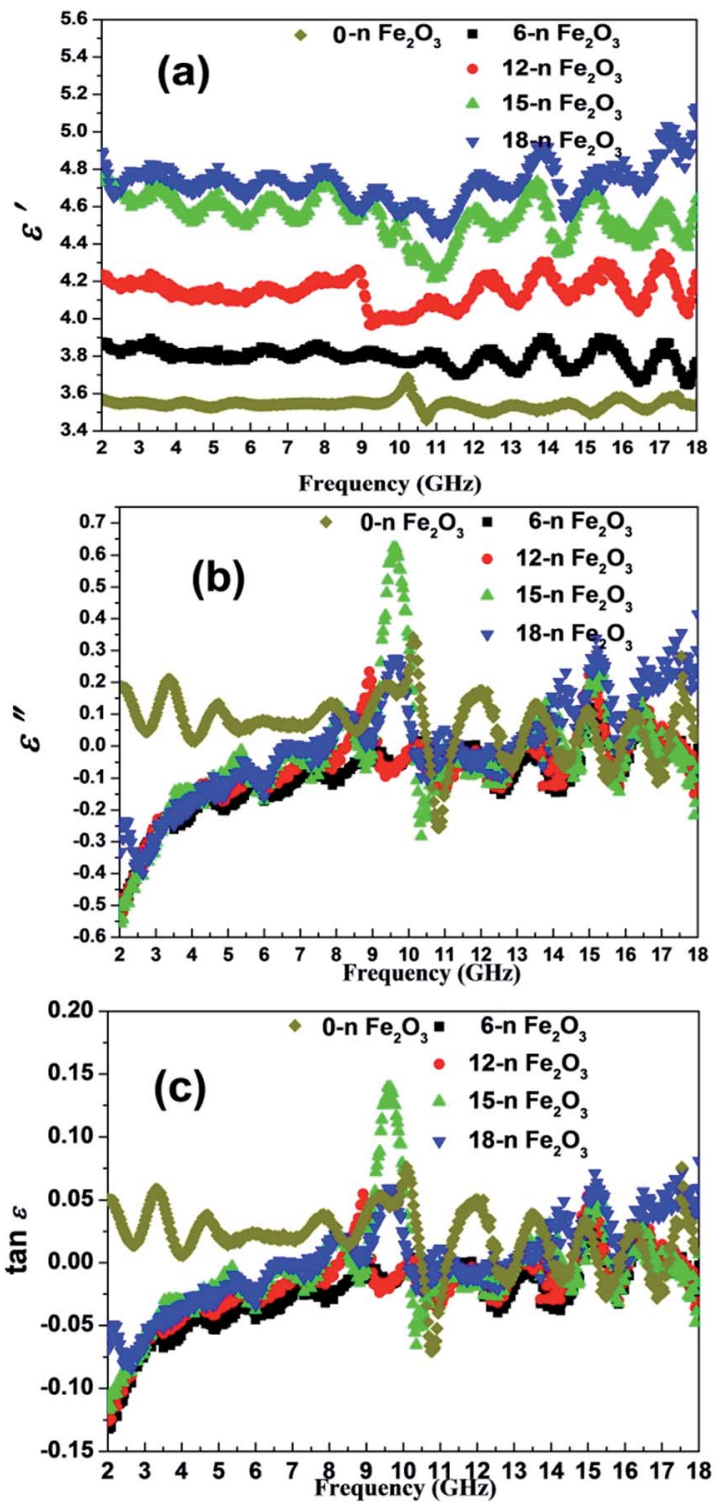

Fig. 6 The dielectric properties of Fe-doped SiCN ceramics with different contents of nano- $\mathrm{Fe}_{2} \mathrm{O}_{3}$ (a) real permittivity; (b) imaginary permittivity; (c) dielectric loss angle tangent.
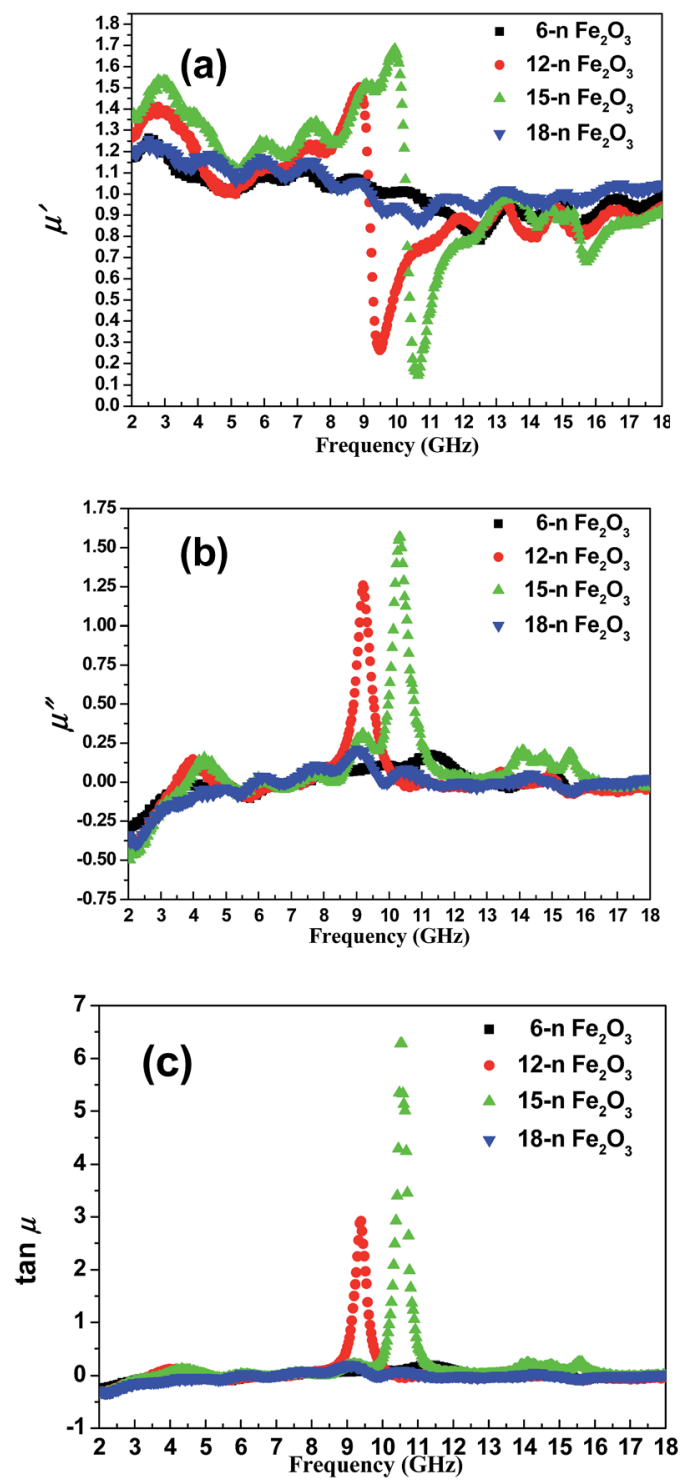

Fig. 7 The magnetic properties of Fe-doped SiCN ceramics with different contents of nano- $\mathrm{Fe}_{2} \mathrm{O}_{3}$ (a) real permeability; (b) imaginary permeability; (c) magnetic loss angle tangent.

which might be caused by the existence of ferromagnetic resonance by $\alpha$-Fe phase. The maximum values of imaginary permittivity and magnetic loss angle tangent of the Fe-doped $\mathrm{SiCN}$ ceramics with $15 \mathrm{wt} \%$ nano- $\mathrm{Fe}_{2} \mathrm{O}_{3}$ were 1.58 and 6.5 , respectively.

The dielectric properties and magnetic properties of $\mathrm{Fe}-$ doped SiCN ceramics changed obviously when samples with $15 \mathrm{wt} \%$ nano- $\mathrm{Fe}_{2} \mathrm{O}_{3}$. Fig. 8 shows the relationship between dielectric parameters (real part and imaginary part) and frequency of Fe-doped $\mathrm{SiCN}$ ceramics $\left(15 \mathrm{wt} \%\right.$ nano- $\left.\mathrm{Fe}_{2} \mathrm{O}_{3}\right)$. The damping harmonic oscillator relaxation of the sample might lead to the resonance peak in 8-12 GHz. It might be caused by the displacement polarization withdrawal of negative and positive ions in the free carbon.

The wave absorbing performance depended on the dielectric and magnetic properties. Fig. 9 shows the reflectance $(R)$ and 


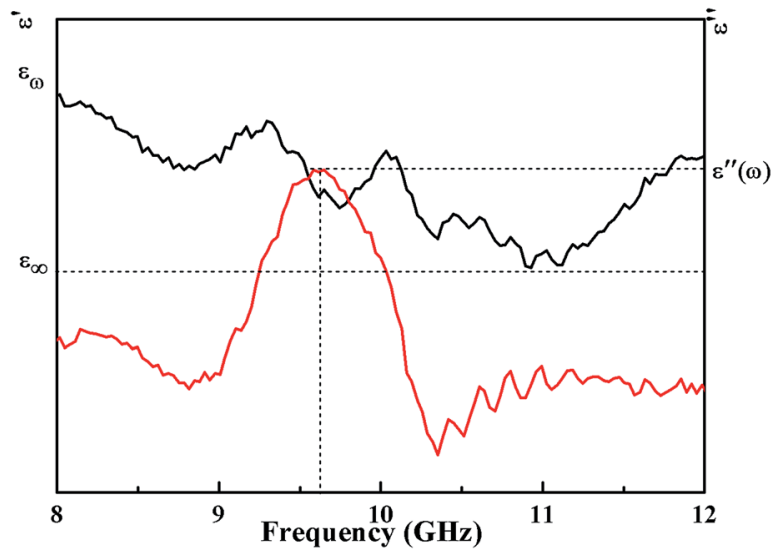

Fig. 8 The real part and imaginary part of Fe-doped SiCN ceramics (15 wt\% nano- $-\mathrm{Fe}_{2} \mathrm{O}_{3}$ ) with different frequency.
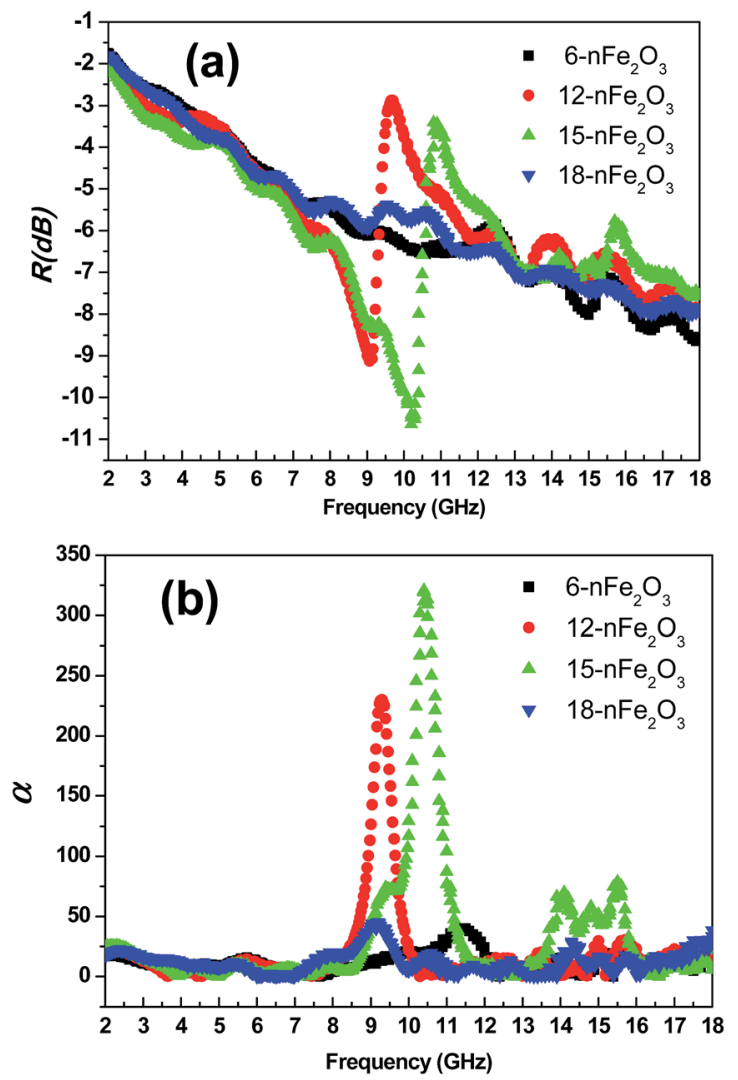

Fig. 9 The wave absorbing properties of Fe-doped SiCN ceramics with different contents of nano- $\mathrm{Fe}_{2} \mathrm{O}_{3}$ (a) reflectance; (b) electromagnetic attenuation coefficient.

electromagnetic attenuation coefficient $(\alpha)$ of Fe-doped SiCN ceramics (thickness $2 \mathrm{~mm}$ ) at $2-18 \mathrm{GHz}$. The value of $R$ decreased with the increasing of frequency except the samples with $15 \mathrm{wt} \%$ and $18 \mathrm{wt} \%$ nano- $\mathrm{Fe}_{2} \mathrm{O}_{3}$ around $10 \mathrm{GHz}$. Similarity, the resonance peaks of $\alpha$-Fe were formed in the same frequency. The phenomenon above might be related to the superposition effect of dielectric loss and magnetic loss. The minimum value of reflectance for Fe-doped SiCN ceramics with $15 \mathrm{wt} \%$ nano-
Table 2 Comparison of wave absorbing properties of Fe-doped SiCN ceramics with other composites from the literature

\begin{tabular}{lllll}
\hline Samples & $\begin{array}{l}\text { Reflectance } \\
\text { in X-band }(\mathrm{dB})\end{array}$ & $\begin{array}{l}\text { Thickness } \\
(\mathrm{mm})\end{array}$ & Tem. $\left({ }^{\circ} \mathrm{C}\right)$ & Ref. \\
\hline Fe-doped SiCN & -11 & 2 & 1100 & This work \\
PDCs-SiBCN & -15.78 & 2.31 & 1650 & 18 \\
PDCs-SiBCN & -13.35 & 2.18 & 1800 & 18 \\
PDCs-SiCN & -18 & 2 & 1700 & 19
\end{tabular}

$\mathrm{Fe}_{2} \mathrm{O}_{3}$ was $-11 \mathrm{~dB}$ at $10.5 \mathrm{GHz}$ and electromagnetic attenuation coefficient reached up to 325 in the same frequency, which indicated that the Fe-doped SiCN ceramics possessed excellent wave absorbing properties.

Table 2 shows the comparison of wave absorbing properties of Fe-doped SiCN ceramics with other composites from the literature. The reflectance of the samples was similar, but the synthesized temperature in this study was much lower than other references. Therefore, the application of Fe-doped SiCN ceramics could greatly reduce the production cost and possess potential prospect in wave adsorbing materials.

\section{Conclusions}

The Fe-doped polymer-derived SiCN ceramics were synthesized by precursor conversion method with different content of nano$\mathrm{Fe}_{2} \mathrm{O}_{3}$. The $\alpha$-Fe and graphite phases were generated during the synthetic process. The existence of $\alpha$-Fe and graphite phases could improve the electromagnetic and wave absorbing properties of the Fe-doped polymer-derived SiCN ceramics greatly. The reflectance and electromagnetic attenuation coefficient of Fe-doped SiCN ceramics with $15 \mathrm{wt} \%$ nano- $\mathrm{Fe}_{2} \mathrm{O}_{3}$ were $-11 \mathrm{~dB}$ and 325 at $10.5 \mathrm{GHz}$, illustrating that the Fe-doped SiCN ceramics possessed excellent wave absorbing properties.

\section{Conflicts of interest}

There are no conflicts to declare.

\section{Acknowledgements}

This work was financially supported by the National Natural Science Foundation of China (No. 51572154) and Shandong Nature Science Foundation of China (2015ZRE27348).

\section{References}

1 D. D. L. Chung, Electromagnetic interference shielding effectiveness of carbon materials, Carbon, 2001, 39(2), 279285.

2 L. Kong, X. Yin, F. Ye, et al., Electromagnetic wave absorption properties of $\mathrm{ZnO}$-based materials modified with $\mathrm{ZnAl}_{2} \mathrm{O}_{4}$ nanograins, J. Phys. Chem. C, 2013, 117(5), 2135-2146.

3 S. Widgeon, G. Mera, Y. Gao, et al., Nanostructure and energetics of carbon-rich SiCN ceramics derived from 
polysilyl carbodiimides: role of the nanodomain interfaces, Chem. Mater., 2012, 24(6), 1181-1191.

4 R. Riedel, A. Kienzle, W. Dressler, et al., A silicoboron carbonitride ceramic stable to $2000{ }^{\circ} \mathrm{C}$, Nature, 1996, 382(6594), 796-798.

5 Y. Wang, Y. Fan, L. Zhang, et al., Polymer-derived SiAlCN ceramics resist oxidation at $1400{ }^{\circ} \mathrm{C}$, Scr. Mater., 2006, 55(4), 295-297.

6 Y. Wang, W. Fei, Y. Fan, et al., Silicoaluminum carbonitride ceramic resist to oxidation/corrosion in water vapor, J. Mater. Res., 2006, 21(07), 1625-1628.

7 R. Riedel, L. M. Ruwisch, L. An, et al., Amorphous silicoboron carbonitride ceramic with very high viscosity at ultra high temperatures, J. Am. Ceram. Soc., 1998, 81, 33413344.

8 X. Li, K. Wang, B. Ma, et al., Effect of acrylic acid additive on electric conductivity of polymer-derived amorphous silicon carbonitride, Ceram. Int., 2015, 41(6), 7971-7976.

9 M. Wilamowska, M. Graczyk-Zajac and R. Riedel, Composite materials based on polymer-derived SiCN ceramic and disordered hard carbons as anodes for lithium-ion batteries, J. Power Sources, 2013, 244, 80-86.

10 L. M. Reinold, Y. Yamada, M. Graczyk-Zajac, et al., The influence of the pyrolysis temperature on the electrochemical behavior of carbon-rich SiCN polymerderived ceramics as anode materials in lithium-ion batteries, J. Power Sources, 2015, 282, 409-415.

11 X. Ren, S. Ebadi, Y. Chen, et al., Characterization of SiCN ceramic material dielectric properties at high temperatures for harsh environment sensing applications, IEEE Trans. Microwave Theory Tech., 2013, 61(2), 960-971.

$12 \mathrm{Q}$. Li, X. Yin and L. Feng, Dielectric properties of $\mathrm{Si}_{3} \mathrm{~N}_{4}-\mathrm{SiCN}$ composite ceramics in X-band, Ceram. Int., 2012, 38(7), 6015-6020.

13 R. Hauser, A. Francis, R. Theismann, et al., Processing and magnetic properties of metal-containing SiCN ceramic micro- and nano-composites, J. Mater. Sci., 2008, 43(12), 4042-4049.

14 M. Malenovska, S. Martinez, M. A. Neouze, et al., Growth of Metal Nanoparticles in a Sol-Gel Silica Thin Film, Eur. J. Inorg. Chem., 2007, 18, 2609-2611.

15 V. S. Gurin, V. P. Petranovskii and N. E. Bogdanchikova, Metal clusters and nano particles assembled in zeolites: an example of stable materials with controllable particle size, Mater. Sci. Eng., C, 2002, 19(1), 327-331.

16 L. Kim, E. Lee, S. J. Cho, et al., Diameter control of carbon nanotubes by changing the concentration of catalytic metal ion solutions, Carbon, 2005, 43(7), 1453-1459.

17 H. Sun, Y. Zhang, H. Gong, et al., High Reactive $\mathrm{MgO}-\mathrm{Y}_{2} \mathrm{O}_{3}$ Nanopowders Via Microwave Combustion Method and Sintering Behavior, Int. J. Appl. Ceram. Technol., 2016, 13(2), 367-372.

18 F. Ye, L. Zhang, X. Yin, et al., Dielectric and EMW absorbing properties of PDCs-SiBCN annealed at different temperatures, J. Eur. Ceram. Soc., 2013, 33(8), 1469-1477.

19 Q. Li, X. Yin, W. Duan, B. Hao, L. Kong and X. Liu, Dielectric and microwave absorption properties of polymer derived SiCN ceramics annealed in $\mathrm{N}_{2}$ atmosphere, J. Eur. Ceram. Soc., 2014, 34, 589-598. 